\title{
Competitividade internacional do complexo cafeeiro brasileiro e paranaense
}

\section{International competitiveness of brazilian and paraná state’s coffe complex}

\section{Vanderlei José Sereia ${ }^{1 *}$; Márcia Regina Gabardo da Camara²; Marcela Vasques Cintra ${ }^{3}$}

\section{Resumo}

O objetivo deste artigo é analisar os determinantes da competitividade das exportações do complexo cafeeiro paranaense entre 1990 e 2003. O estudo pretende sistematizar: a literatura recente sobre o tema, enfocando a competitividade de um dos principais produtos da pauta de exportações brasileira e do Paraná. Realizou-se a revisão crítica da literatura das teorias do comércio internacional e da competitividade e em seguida, caracterizou-se a dinâmica do complexo cafeeiro do brasileiro e paranaense. $\mathrm{O}$ artigo identifica as vantagens competitivas do café paranaense (verde, torrado, solúvel e especial) em relação aos países concorrentes; discute as barreiras às importações impostas ao café brasileiro pelos países importadores; e finaliza com as possíveis políticas públicas e privadas favoráveis à competitividade das exportações de café.

Palavras-chave: Comércio internacional, modelo CMS, exportação de café

\begin{abstract}
The objective of this article is to analyze the determinants aspects of the competitiveness of the exportations of the coffee complex in Paraná State between 1990 and 2003. The study intends to systematize: the recent literature on the subject, focusing the competitiveness of the main products of the brazilian guideline of exportations. A critical review of literature was made about the theories of international trade and competitiveness. It was characterized the dynamics of the complex of Brazilian coffee. The article identifies the competitive advantages of the Paraná coffee (green, roasted, soluble and special) in relation to the competing countries; discusses the barriers to imports imposed to the brazilian coffee by the importing countries, and ends with the possible public and private policies favorable to the competitiveness of the coffee exportations.
\end{abstract}

Key words: International trade, model Constant-Market-Share, exportations coffee

\footnotetext{
1 Professor do Departamento de Economia UEL, Mestre em Economia pela UnB, Telefone: (043) 33714255, E-mail: sereia@uel. br

2 Professora do Departamento de Economia da Universidade Estadual de Londrina (UEL) - PPA/UEL/UEM, Doutora em Economia pela USP, Telefone: (043) 33714255, - E-mail: mgabardo@sercomtel.com.br

3 Economista, UEL-E-mail: mvcintra@londrina.net

* Autor para correspondência
} 


\section{Introdução}

O interesse pelo conceito de cadeia produtiva é recenteesefazimportanteparaoestudoecompreensão da produção agrícola e o gerenciamento nas suas diversas dimensões - social, econômica, política, tecnológica, biológica, entre outras. A coordenação das cadeias tem sido o foco de muitos estudos de agribusiness, em particular para as cadeias expostas à competição internacional e às crescentes pressões dos consumidores, requerendo continua adaptação (CASTRO; LIMA; HOEFLICH, 2002).

A relevância deste estudo se verifica na tendência do negócio agrícola brasileiro em assimilar a tecnologia como fator de competitividade e de sucesso do negócio. No caso do Brasil em geral e do Paraná em particular, além do desenvolvimento da tecnologia agrícola, a disponibilidade de terras e a mão-de-obra barata tornam o país competitivo internacionalmente.

O café ocupa posição de destaque na pauta de exportações do Brasil e do Paraná desde o início do século XX e é um dos produtos mais representativos da economia brasileira com relevante participação no desenvolvimento nacional, contribuindo para os setores de indústria e serviço, além do próprio setor primário. As exportações de café verde e industrializado (solúvel e torrado e moído), além de garantir divisas ao país, geram impactos na indução do produto interno bruto (PIB) e na absorção de mão-de-obra. A contribuição da cafeicultura para o desenvolvimento humano deve-se à complexidade da cadeia produtiva, que requer em diferentes proporções, mão-de-obra não-qualificada e qualificada.

O Brasil é o maior produtor e ofertante mundial de café arábica e tem garantido a manutenção e o crescimento da participação no mercado internacional devido ao custo de produção mais baixo, porém os cafés da Colômbia, Guatemala, Costa Rica e Quênia, entre outros, têm sido mais valorizados pela qualidade. No caso do café robusta, o Vietnã, segundo maior produtor mundial, tem apresentado custos de produção mais competitivos e produtividade média mais elevada do que a do Brasil, reduzindo a participação da produção brasileira em alguns mercados já que o café robusta tem se mostrado muito mais um bem substituto do que complementar ao café arábica (SAES; NAKAZONE, 2002).

Além do custo de produção, a expansão do mercado de cafés especiais também é um fator determinante da competitividade. Fatores como qualidade, serviços pré e pós-venda, capacidade para modificar especificações adaptando-se rapidamente às necessidades do consumidor, baixa quantidade de defeitos, marketing e capacidade para concorrer em prazo de entrega representam a base da competitividade nos mercados mundiais. A crescente percepção de que estes fatores não são dados, como por exemplo, recursos naturais abundantes e mão-de-obra barata, mas que precisam ser construídos ao longo do tempo num processo de aprendizado contínuo e envolvendo todos os agentes econômicos voltados para a produção, tornou a busca de competitividade uma das preocupações centrais dos governos e das indústrias de todos os países (GRASSI, 1997).

A queda dos preços internacionais do café reduziu sua participação na pauta de exportação brasileira e paranaense, ficando atrás dos complexos soja, açúcar e carne de frango no período em estudo. Além disso, a falta de coordenação entre os segmentos do agronegócio e a ausência de valorização da qualidade do café brasileiro entravam à concorrência.

As barreiras tarifárias ao café industrializado (solúvel e torrado e moído) também são responsáveis pela participação decrescente das exportações brasileiras. A indústria de solúvel, por estar voltada ao mercado externo, é prejudicada tanto pelo aumento da produção de café robusta na Ásia quanto pelas barreiras tarifárias na União Européia, além da questão tributária. Por outro lado, a indústria de café torrado e moído, voltada para o mercado interno, vem se consolidando com o ingresso de empresas 
multinacionais atraídas pelo potencial do mercado brasileiro - segundo maior consumidor mundial de café.

As vantagens competitivas oriundas da eficiência organizacional, das inovações tecnológicas e da qualidade dos produtos representam o principal instrumento para que as empresas sejam mais eficientes e competitivas e sobrevivam no ambiente de concorrência (CASTRO; LIMA; HOEFLICH, 2002).

\section{Comércio internacional}

\section{Teorias do Comércio Internacional}

De acordo com Smith (1776 apud GONÇALVES et al. ,1998), o comércio entre duas nações baseiase nas vantagens absolutas. Quando uma nação é mais eficiente do que outra na produção de uma “commodity", porém é menos eficiente do que a outra nação na produção de uma segunda "commodity", ambas as nações podem ganhar trocando parte de sua produção com a outra nação pela "commodity" de sua desvantagem absoluta. Isto é, para Smith, o comércio internacional seria possível tão-somente quando o tempo de trabalho necessário para produzir pelo menos um produto fosse inferior àquele do exterior. Uma vez que o comércio internacional aumenta o mercado para os produtos produzidos domesticamente, ele permite o aprofundamento da divisão do trabalho, contribuindo para aumentar a riqueza das nações. O livre comércio é um poderoso mecanismo capaz de promover aumento da produção por meio da especialização e, com as trocas, aumentar o consumo e, conseqüentemente, o bem-estar das populações dos países que participam do comércio internacional (CARVALHO; SILVA, 2000).

Coube a David Ricardo (1982) explicar a base do comércio e os ganhos com ele obtidos - a lei das vantagens comparativas. Segundo o autor, o comércio internacional e os ganhos do comércio são possíveis pela diferença dos custos relativos ou comparativos derivados da produtividade do trabalho, ou seja, cada país se especializa em atividades produtivas em que sua produtividade comparada (relativa) é mais elevada, ou seja, sua desvantagem absoluta é menor. À medida que cada nação se especializa na produção da "commodity" de sua vantagem comparativa, incorre em custos de oportunidades crescentes. Por isso, a lei das vantagens comparativas também é conhecida como a lei dos custos comparativos. (SALVATORE, 2000)

As condições de oferta, que dependem de sua dotação de terra, mão-de-obra e capital, bem como de sua tecnologia, diferem de um país para outro, levando às diferenças de preços entre os países. Alguns países têm combinações de recursos necessários para determinadas atividades, sendo consideradas fontes de vantagens comparativas. De acordo com Williamson (1989), existem respostas compatíveis com o modelo de um só fator de Ricardo: as diferenças poderiam ser causadas por condições climáticas ou diferentes níveis de tecnologia.

Somente no século $\mathrm{XX}$ surgem às teorias modernas de comércio internacional, baseadas no custo comparativo - oportunidades, em oposição às teorias clássicas que se apóiam no custo comparativo - trabalho. Segundo Hecksher e Ohlin (apud MAIA, 1998), as diferenças de custos de produção de uma mesma mercadoria de uma nação para outra são conseqüências de várias circunstâncias, tais como: custos dos insumos, proporção dos fatores de produção (natureza, trabalho e capital), imobilidade da mão-de-obra, e dificuldades na transferência dos fatores de produção de um país para outro.

$\mathrm{O}$ teorema de $\mathrm{H}-\mathrm{O}$ afirma que cada país se especializa e exporta o bem que requer utilização mais intensiva de seu fator de produção abundante (CARVALHO; SILVA, 2000). Esse modelo mostra que as vantagens comparativas são influenciadas pela interação entre os recursos da nação (a abundância relativa dos fatores de produção) e a tecnologia da produção (que influencia a intensidade relativa com a qual fatores diferentes de produção são usados na produção de bens distintos) (KRUGMAN; OBSTFELD, 1999). Assim, o teorema de H-O 
também é chamado de teoria das proporções dos fatores ou das dotações de fatores.

$\mathrm{O}$ equilíbrio geral da teoria de $\mathrm{H}-\mathrm{O}$ é verificado pela interação dos gostos e a distribuição da renda que determina a demanda das "commodities", ou seja, a demanda por fatores de produção deriva da demanda das "commodities". A demanda e a oferta dos fatores determina o preço dos fatores de produção em concorrência perfeita. Esse preço associado à tecnologia determina o preço das "commodities" finais. A diferença nos preços relativos das "commodities" entre as nações determina a vantagem comparativa e o padrão de comércio (SALVATORE, 2000). Portanto, o comércio de bens é uma forma indireta de comercializar os fatores de produção.

O Teorema Hecksher-Ohlin-Samuelson (H-OS) ou teoria da equalização dos preços dos fatores enuncia que o comércio internacional equaliza os preços dos fatores de produção entre as nações. Com o comércio cada país se especializa na produção do bem em que possui vantagem comparativa (intensivo em fator de produção abundante, mais barato). Com o aumento da produção, a demanda por este fator abundante aumenta elevando também seu preço. Da mesma forma, a diminuição da demanda pelo fator escasso (mais caro) faz com que seu preço caia. Enquanto houver diferenças entre os preços relativos dos fatores (trabalho e capital), o comércio continuará se expandindo. (KRUGMAN; OBSTFELD, 1999)

Enquanto o teorema $\mathrm{H}-\mathrm{O}-\mathrm{S}$ mostra que o preço dos fatores, dadas certas condições, é independente de sua dotação, o teorema de Stolper-Samuelson revela que os preços dos fatores dependem do preço das mercadorias que produzem. Segundo esse teorema, o comércio beneficia o fator de produção abundante em detrimento do fator escasso de cada país. O pleno emprego e a equalização do preço dos fatores garantem que o fator de produção abundante se beneficie com o comércio, possibilitando a redistribuição da renda. De acordo com Williamson (1989), os detentores do fator de produção escasso podem aumentar sua renda real em termos absolutos através da proteção restritiva de importações, mesmo que a sociedade como um todo perca..

A teoria de Hecksher-Ohlin (H-O) pressupõe retornos constantes à escala, mas o comércio internacional pode se basear também em retornos crescentes à escala. Quando as economias de escala se aplicam no nível das indústrias em vez de no nível das firmas individuais, elas são chamadas de economias externas. Alfred Marshall, ao realizar um estudo das concentrações geográficas da indústria, verificou que as economias podiam ser explicadas por outros elementos e não repousavam na existência de recursos naturais. Marshall argumentou que havia três razões que induziam um grupo de firmas a ser mais eficiente que a firma individual de forma isolada: a habilidade de o grupo manter fornecedores especializados; a maneira pela qual uma indústria geograficamente concentrada permite um mercado comum de trabalho; e a maneira pela qual uma indústria geograficamente concentrada ajuda a transbordar o conhecimento. Estes fatores continuam válidos atualmente (KRUGMAN; OBSTFELD, 1999).

O debate sobre concorrência imperfeita (monopolística), no entanto, é o campo mais relevante para a discussão do comércio internacional no período recente porque a maior parte do comércio mundial ocorre não entre países que se especializam na produção de produtos distintos, mas entre países que comercializam os mesmos produtos. Sob condições de concorrência imperfeita, há incentivos para que os governos subsidiem a exportação ou pesquisas para o desenvolvimento de novos produtos a serem exportados no intuito de obter lucros mais altos em mercados estrangeiros. Entretanto, se houver retaliação por parte de outros governos, haverá perdas para todos, podendo ser necessários acordos para evitar que o processo se inicie.

Os modelos de defasagem tecnológica e de ciclo do produto são considerados extensões dinâmicas do modelo estático de H-O. De acordo com o modelo de 
defasagem tecnológica esboçado por Posner (1961 apud SALVATORE, 2000), uma grande parte do comércio entre os países industrializados se baseia na introdução de novos produtos e novos processos de produção. Estes concedem à nação inovadora $o$ monopólio temporário do mercado mundial, que é baseado em patentes e direitos autorais, concedidos para estimular o fluxo das invenções. O autor também distinguiu economias de escala dinâmica das de escala estática: quando o progresso técnico ocorre, os custos unitários para determinada firma serão menores hoje do que ontem, ou seja, embora todas as empresas sejam beneficiadas com o progresso técnico, somente a experiência passada bem sucedida da função P \& D em certas empresas merece a denominação de economia de escala dinâmica (GUIMARÃES, 1997).

Guimarães (1997) aponta que o modelo de ciclo do produto está estreitamente relacionado à teoria do investimento direto. Os desenvolvimentos teóricos recentes tratam o investimento externo direto como uma das formas do processo de internacionalização da produção. A internacionalização da produção ocorre sempre que residentes de um país têm acesso a bens ou serviços originários de outro país. Este processo pode ocorrer por meio de três formas: comércio internacional, investimento externo direto e a relação contratual (GONÇALVES et al., 1998).

Grande parcela dos investimentos diretos internacionais atualmente é efetuada pelas corporações multinacionais (CMNs). Nesse contexto, Dunning(1988) discute os determinantes da decisão de produzir no estrangeiro como uma combinação de vantagens depropriedade, localização e internacionalização. Segundo o paradigma eclético de Dunning, a decisão de internacionalizar a produção se baseia em aproveitar as vantagens de localização oferecidas por um país ou região determinados, fazendo uso de capacidades próprias (vantagens de propriedade) que the permitem posicionar-se melhor que outros investidores no mercado receptor .
As empresas fortemente voltadas para o comércio internacional, seja através de exportações ou de produção externa e/ou facilidades de vendas, são mais lucrativas e apresentam variabilidade muito menor nos lucros do que as empresas puramente domésticas (SALVATORE, 2000). Kenen (1998) argumenta que os produtos diferenciados, as vantagens tecnológicas e economias de escala dão às grandes empresas estabelecidas vantagem competitiva sobre empresas locais menores e mais novas. Isto envolve a integração horizontal, ou a produção no exterior de um produto diferenciado também produzido internamente.

A maior parte dos investimentos externos diretos nos países em desenvolvimento é realizada pelo processo de integração vertical, ou seja, pela obtenção do controle de uma matéria-prima necessária para assegurar sua oferta ininterrupta ao menor custo possível. A distribuição regional dos investimentos externos diretos em todo o mundo também depende da proximidade geográfica ou das relações comerciais estabelecidas (SALVATORE, 2000).

Segundo Salvatore (2000), as questões relativas aos custos de transporte (despesas com frete, custos de embarque e desembarque, seguros e despesas com juros pelo período em que as mercadorias estão em trânsito) explicam por que a maior parte dos bens e serviços não é comerciada internacionalmente. Além disso, os padrões ambientais (níveis permitidos pela população de poluição do ar, da água, térmica e resultante do lançamento de lixo) também afetam a localização da indústria e o comércio internacional. Apesar do notável desenvolvimento teórico observado nas vertentes apresentadas, explicativas do padrão de comércio internacional, não se tem ainda uma comprovação com respeito aos seus determinantes (GUIMARÃES, 1997).

\section{Entendendo a competitividade}

A análise da competitividade tem origem no princípio das Vantagens Comparativas Relativas de 
Ricardo. O comércio entre as nações ativa o processo competitivo através da busca por maiores vantagens, ou seja, o fluxo internacional de mercadorias depende dos preços relativos dos fatores de produção (trabalho, matérias-primas, infra-estrutura e capital) , é influenciado pelas diferenças nas dotações de fatores, tecnologia disponível, economias de escala, padrões de consumo e pela estrutura de mercado.

As primeiras discussões surgem no âmbito da Teoria da Organização Industrial no Modelo Estrutura-Conduta-Desempenho. As vantagens competitivas são conquistadas ao nível da firma e as forças competitivas determinantes da atratividade estrutural a longo prazo de um setor são: intensidade da rivalidade capitalista, a existência de ameaça de novos entrantes, as ameaças de substitutos, o poder de negociação com compradores e o poder de negociação com fornecedores (FERRARO; SEREIA; CAMARA, 2003).

Segundo a definição proposta em 1985 pela Comissão da Presidência dos EUA sobre Competitividade Industrial;

Competitividade para uma nação é o grau pelo qual ela pode, sob condições livres e justas de mercado, produzir bens e serviços que se submetam satisfatoriamente ao teste dos mercados internacionais enquanto, simultaneamente, mantenha e expanda a renda real de seus cidadãos. Competitividade é a base para o nível de vida de uma nação. É também fundamental à expansão das oportunidades de emprego e para a capacidade de uma nação cumprir suas obrigações internacionais (COUTINHO; FERRAZ, 1994, p. 17).

A maior parte dos estudos costuma tratar a competitividade como um fenômeno diretamente relacionado às características de desempenho ou de eficiência técnica e alocativa apresentadas por empresas e produtos e a considerar a competitividade das nações como a agregação desses resultados. A competitividade revelada é vista como um desempenho e é expressa pela participação no mercado (market-share) alcançada por uma firma em um mercado em certo momento do tempo. A participação das exportações da firma ou conjunto de firmas (indústria ou nação) no comércio internacional total da mercadoria aparece como seu indicador mais imediato. A competitividade é uma variável "ex-post" que sintetiza os fatores preço e não-preço (qualidade de produtos e de fabricação, habilidade de servir ao mercado, capacidade de diferenciação de produtos) (FERRAZ; KUPFER; HAGUENAUER, 1995).

A competitividade potencial é vista como eficiência e é determinada pela relação insumoproduto praticada pela firma; isto é, capacidade da empresa de converter insumos em produtos com o máximo de rendimento. Os indicadores são buscados em comparativos de custos e preços, coeficientes técnicos ou produtividade dos fatores , em termos das best-practices verificadas na indústria internacional. A competitividade é um fenômeno "ex-ante", ou seja, reflete o grau de capacitação detido pelas firmas, que se traduz nas técnicas por elas praticadas. O desempenho obtido no mercado seria uma conseqüência inexorável dessa capacitação .Ferraz, Kupfer e Haguenauer (1995) afirmam que o desempenho e a eficiência são enfoques limitados por serem estáticos, analisando apenas o comportamento passado dos indicadores, sem elucidar as relações causais que mantêm com a evolução da competitividade.

Uma das críticas aos estudos empíricos que se utilizam das visões tradicionais de competitividade, baseadas em vertentes estáticas da Teoria do Comércio Internacional (notadamente as relativas a vantagens comparativas), com forte viés macroeconômico, ou que se utilizam de poucas variáveis e fórmulas prontas, é que eles são insuficientes para explicar os termos atuais de rápida mudança tecnológica e organizacional, acirramento da concorrência e globalização. Segundo Grassi (1997), o conceito de competitividade com forte caráter dinâmico deve ser buscado em outras bases: a Nova Teoria do Comércio e os estudos de autores neo-schumpeterianos. No ambiente de concorrência schumpeteriana, a empresa procura orientar-se pelo 
padrão de concorrência vigente no setor naquele momento para tentar obter - ou renovar - as vantagens competitivas que a permitam manter uma posição de destaque ante a concorrência.

Kupfer(1992)afirma que opadrãodeconcorrência é a variável determinante e a competitividade, a variável determinada ou de resultado. A noção de competitividade sistêmica estabelece que ao mesmo tempo em que o desempenho empresarial depende, ele é também resultado de fatores situados fora do âmbito das empresas e da estrutura industrial da qual fazem parte, como a ordenação macroeconômica, as infra-estruturas, o sistema político-institucional e as características sócio-econômicas dos mercados nacionais. Todos estes fatores são específicos a cada contexto nacional e devem ser considerados nas ações públicas ou privadas de indução de competitividade (COUTINHO; FERRAZ, 1994).

Para Baumann (1996), as estratégias empresariais são definidas a partir da identificação das demandas dos consumidores (em lugar da produção maciça de bens estocáveis). A competição é crescentemente baseada em vantagens competitivas construídas (em lugar de a decisão de investir ser função da disponibilidade de recursos) e os custos do processo produtivo e da cadeia de distribuição passam a ter um papel cada vez mais determinante das estratégias empresariais do que os custos de fatores.

Segundo Schumpeter (1988), o desenvolvimento econômico decorre da introdução de inovações pelos empresários, ou seja, novas formas de combinar os meios de produção disponíveis. Estas novas combinações podem incluir a criação de novos produtos, a introdução de novos métodos de produção, a abertura de um novo mercado, a conquista de uma nova fonte de matérias-primas e a criação de uma nova forma de organização de uma indústria. Nesse sentido, o desenvolvimento é pensado como um processo de destruição criadora.

Segundo Porter(1986), o fortalecimento da posição competitiva depende da implementação de estratégias genéricas de competitividade de três dimensões: a) liderança no custo total: custo baixo em relação aos concorrentes é o tema central de toda a estratégia;

b) diferenciação: criação de projeto ou imagem da marca, tecnologia, peculiaridades, serviços sob encomenda, rede de fornecedores, ou outras dimensões que sejam consideradas únicas;

c) enfoque: capacidade de atender seu alvo estratégico estreito mais efetiva e eficientemente do que os concorrentes que estão competindo de forma mais ampla.

No agribusiness, a liderança em custo é essencial, pois boa parte dos produtos é classificada como "commodities", que requerem amplo volume de operação para obtenção de ganhos nas economias de escala e de escopo e, assim, reduzir os custos unitários de produção e distribuição. A diferenciação de produtos e serviços através da pesquisa e desenvolvimento, tecnologia e inovação e ações de marketing, vendas e distribuição deve ampliar a taxa de lançamento de produtos e serviços, oferecendo novos produtos e agregando diferenciais às "commodities" tradicionais. A diferenciação contribui para o aumento do valor agregado dos produtos e serviços do agronegócio. Quanto ao enfoque, as empresas devem escolher se vão atuar orientadas para um alvo amplo (mercado mundial ou nacional) ou estreito (mercados locais ou regionais). As estratégias de enfoque podem ser aplicadas em um ou mais processos operacionais, como suprimento de insumos ou matérias-primas, a produção agropecuária ou industrial, e as atividades de marketing, vendas e distribuição (WEDECKIN, 2002).

As empresas dos setores de "commodities" convivem com acirrada concorrência e devem ser capazes de explorar ao máximo todas as fontes de redução de custos: operar processos tecnologicamente atualizados, apresentar excelência na gestão da produção, montar sistemas eficientes de abastecimento de matérias-primas (inclusive apoiando esforços para aumentar sua eficiência ou financiando produtores agrícolas) e dispor de 
logística adequada de movimentação de produtos (FERRAZ; KUPFER; HAGUENAUER, 1995).

Segundo Gonçalves (1996), o aumento dos riscos e incertezas no que se refere às transações internacionais repercute diretamente nas atividades de exportação e importação e, como resultado, afeta a composição e os níveis de produção, emprego e investimento. O nível geral de preços pode ser também afetado pela volatilidade e pelo desalinhamento cambial na medida em que os agentes econômicos fazem reajustes de preços para compensar o risco cambial.

No curto prazo, a variável crucial da competitividade internacional continua sendo a taxa de câmbio, plano em que sobram divergências no país (fora e dentro do governo). No longo prazo, o aumento da produtividade e da qualidade na produção industrial brasileira serão essenciais para a competitividade internacional, contribuindo para melhores resultados na balança comercial; por outro lado, se a desvalorização da taxa de câmbio for menor; maior será a estabilidade de preços. Conseqüentemente, sempre que uma política de competitividade industrial puder ajudar a fortalecer a produtividade e qualidade da indústria brasileira, ela será elemento de uma política de estabilidade macroeconômica (BIELSCHOWSKY; STUMPO, 1996).

No plano doméstico é fundamental assegurar coordenação e consistência entre as diversas políticas de construção da competitividade. Os governos nacionais exercem forte influência sobre os determinantes da competitividade, podendo alterálos de forma negativa ou positiva. Para Coutinho e Ferraz (1994), a intervenção do Estado, antes baseada em instrumentos de proteção e na concessão indiscriminada de subsídios fiscais e financeiros à exportação, deve evoluir em direção à coordenação e ao fomento estruturante, com ênfase na difusão das inovações técnicas, organizacionais e financeiras e na capacitação tecnológica das empresas.

Em países com vocação agrícola, como o Brasil, a infra-estrutura de pesquisa e desenvolvimento de novas variedades de sementes, novas técnicas de cultivo ou, ainda, de manejo de safras, tem-se revelado essencial para a competitividade da agroindústria, uma vez que a maior dispersão econômica e geográfica característica da agricultura restringe a viabilidade da P\&Din-house (intramuros), delimitando um importante campo para a atuação das entidades tecnológicas (COUTINHO; FERRAZ, 1994).

Segundo Ferraz, Kupfer e Haguenauer (1995), os novos desafios competitivos do grupo "commodities" são: agregar valor à pauta de produtos para abrir novos mercados; associar parâmetros energéticos e ambientais ao uso da base de recursos naturais, fortalecer o porte empresarial e internacionalizar as operações; e desenvolver novas engenharias financeiras em parcerias público-privadas, além de atuar em condições de maior concorrência e sobregime de regulação mais restritivo no que diz respeito à questão ambiental. Entretanto, os efeitos socialmente adversos provocados pela busca da competitividade - desemprego estrutural, salários decrescentes e crescente desigualdade - já eram preocupações de Adam Smith em relação aos conflitos potenciais entre o interesse público e a conduta dos empresários.

O desenvolvimento com competitividade pode criar novos e melhores empregos, assim como qualidade de trabalho e de vida, mas deve estar ligado a um conjunto de diretrizes e objetivos capazes de criar perspectivas de crescimento econômico e redução das distâncias sociais. Para a maioria dos setores da agroindústria, um mercado interno forte é fundamental para a inserção competitiva dinâmica no comércio internacional. A principal vantagem competitiva da indústria brasileira é o tamanho do mercado interno. $\mathrm{O}$ potencial do mercado poderia ser maior se não enfrentasse as restrições decorrentes da desigualdade na distribuição da renda e marginalização de parcela significativa da população do consumo de bens industriais. A disparidade nos níveis de renda e consumo da população também dá margem a uma elevada heterogeneidade de capacitações competitivas na indústria brasileira (COUTINHO; FERRAZ, 1994). 
As diversas acepções do conceito de competitividade internacional existentes na literatura nacional e internacional proporcionam uma gama diversificada de metodologias para analisá-la. A variedade de indicadores utilizados explica-se também pelos objetivos divergentes que orientam a sua construção, sejam estes de natureza analítica ou descritiva.

De acordo com o Estudo da Competitividade da Indústria Brasileira (ECIB), o complexo agroindustrial do café está entre os setores com capacidade competitiva, pois apresenta níveis elevados de eficiência produtiva e excelente desempenho no comércio exterior. No entanto, a capacitação competitiva desses setores está concentrada principalmente em "commodities" - produtos de baixo valor agregado, que enfrentam excesso de oferta mundial e estagnação de mercados, o que significa preços declinantes no mercado mundial. (COUTINHO; FERRAZ, 1994).

Do ponto de vista da política de competitividade, Saes e Nakazone (2002), destacam no estudo de cadeias produtivas abordando a cadeia de café, que prevalecem ações que reforçam posições competitivas já alcançadas, sobretudo no que tange à agregação de valornas exportações (via diferenciação de produtos) e no apoio à internacionalização de empresas, especialmente para melhorar e ou controlar a distribuição nos mercados externos (via marcas próprias ou redes).

\section{O complexo agroindustrial do café}

O mercado de café tem uma longa história de regulamentação, que se iniciou na órbita da comercialização em 1906. Na época, o Brasil, que detinha três quartos da produção mundial e dependia basicamente do produto para suas receitas cambiais, deu início a uma política sistemática de sustentação de preços do café. Antes da constituição do primeiro Acordo Internacional do Café (AIC) em 1962, no âmbito da Organização Internacional do Café (OIC), o governo brasileiro atuava diretamente no processo de formação dos preços externos com o intuito de maximizar as receitas provenientes deste produto. O Brasil fazia uso do seu poder de monopólio e administrava a oferta ao mercado externo e esta iniciativa gerava, consequentemente, escassez artificial do produto (BRAGANÇA, 2000).

Segundo Saes e Nakazone (2002), no plano interno a regulamentação acabou coordenando todo o sistema cafeeiro (produção rural, indústria de transformação e distribuição/consumo). Desde o início dessa política vários organismos foram criados, mas foi a cargo do Instituto Brasileiro do Café (IBC) que a coordenação dos segmentos não só determinou a dinâmica particular de cada um destes segmentos como também condicionou o desempenho do café brasileiro no mercado externo. Este é o motivo que explica porque a partir da década de 60, quando o IBC se vê diante de uma supersafra e estoques duas vezes maiores que a demanda mundial, decidindo implementar a "Campanha para o aumento do Consumo Interno de Café" e criar a indústria de solúvel. Tais medidas tinham como objetivo minimizar os custos de carregamento de estoques e procuravam manter a política de valorização do produto no mercado internacional. Como líder do mercado produtor de café, o Brasil teve um papel central no sucesso da política de sustentação dos preços no mercado mundial, mas em muitos momentos, os acordos foram efetivados porque o país se sujeitou a reduzir sua participação, firmando-se como ofertante residual, isto é, retendo os estoques.

A estratégia adotada pelo Brasil durante o período de vigência do AIC é um dos elementos que explicam o declínio da sua participação no mercado mundial de café. Mantendo preços artificialmente elevados, muitos países expandiram suas áreas cultivadas, pressionando a cota brasileira (BRAGANÇA, 2000). No final da década de 80 , observou-se uma postura diferente do Brasil nas negociações das cláusulas econômicas do AIC: não aceitou mais reduções na sua participação no mercado internacional, o que implicou o rompimento do AIC em 1989. O excesso 
de oferta mundial, no início dos anos 90, resultou em queda vertiginosa dos preços e crise, não só para o setor, como para vários países, cuja economia depende significativamente da renda do produto (caso de Burundi e Ruanda).

A crise induziu a institucionalização de um novo organismo de regulamentação, a Associação dos Países Produtores de Café (APPC) em 1993, com o objetivo principal de reordenar a oferta e reinstalar o sistema de cotas. Porém, importantes produtores não participam da organização (Vietnã e México) e ao contrário da OIC, também não congrega os países consumidores que tinham um papel importante na fiscalização do sistema de cotas. Já a partir de 1998, quando a oferta começou a crescer, a dificuldade de administração do sistema foi percebida, pois vários países não cumpriram a cota acordada. Apesar de o Brasil ter implementado um rígido controle de embarques, que significou perda de participação do mercado, os preços continuaram em forte queda com o ingresso no mercado de cafés de outras origens (SAES; NAKAZONE, 2002).

Os resultados de 50 anos de política de restrição da oferta incluem a queda de participação de mercado e a imagem sedimentada no mercado internacional de que o café brasileiro tem uma qualidade média e serve apenas para formar blends. Segundo Saes e Nakazone (2002), a competitividade brasileira tem sido afetada pelo diferencial de preços entre o café brasileiro e os cafés suaves, considerados de maior qualidade. Também se verifica o crescimento da participação do café robusta no mercado internacional, particularmente do Vietnã, que aliado às novas tecnologias na formação de blends tornouse um substituto próximo do café brasileiro, ou seja, o café brasileiro passou a ser extremamente elástico. Entre os desafios da competitividade setorial está o ambiente institucional, que define as regras para o setor e a desregulamentação que coloca em discussão as ações (uso de instrumentos) que podem intensificar e melhorar a coordenação dos agentes, na ausência de incentivos para a adoção pelos agentes individuais.
No Brasil, depois da extinção do IBC, instalou-se oficialmente a "Comissão Especial da Auto Gestão do Funcafé" em 1996, formada na Câmara dos Deputados, com a incumbência de institucionalizar um novo modelo de gestão da cafeicultura brasileira. Neste mesmo ano, foi criado o Conselho Deliberativo da Economia Cafeeira (CDPC), que possui as seguintes atribuições: aprovação de planos de safra, aprovação de políticas de estocagem, administração dos armazéns de café e a aprovação da proposta orçamentária referente aos recursos do Fundo de Defesa da Economia Cafeeira (FUNCAFÉ). Em 1999, criou-se o Conselho dos Exportadores de Café Verde do Brasil (CECAFÉ), que tem por objetivo aumentar a margem do setor através da congregação e da representação das empresas que exportam café verde (BRAGANÇA, 2000).

\section{As barreiras às exportações brasileiras do agronegócio}

Bragança (2000) afirma que não há barreiras à entrada do café verde no mercado americano e europeu, os principais destinos das exportações brasileiras, por praticarem Draw Back tornam-se grandes exportadores de café processado. No caso do café torrado, a entrada no mercado internacional exige uma série de pré-requisitos que dificultam a exportação. Já para o café solúvel, existem barreiras tarifárias desiguais entre os países concorrentes.

O estudo sobre as Barreiras aos produtos $e$ serviços brasileiros, realizado Barreiras (2002), destaca dois elementos que merecem atenção pelas futuras implicações no tocante à facilitação de comércio. Em primeiro lugar, as novas legislações e regulamentações adotadas pelos Estados Unidos, por motivo de segurança: "Bioterrorism Act", iniciativas da alfândega, como "Advanced cargo manifests" e "Container Security Initiative" ; apesar de não terem objetivo restritivo, eles sinalizam dificuldades adicionais de acesso. $\mathrm{O}$ segundo referese à decisão norte-americana de apresentar ofertas de liberalização comercial no âmbito hemisférico em 
base bilateral e não para todos os países, deixando de aplicar o princípio da nação mais favorecida, o que pode gerar uma situação discriminatória contra o Brasil por ser o país mais competitivo em um grande número de produtos agrícolas.

Outro fato importante destacado pelo embaixador Rubens Antonio Barbosa foi à audiência pública sobre "A crise do café na América Latina", realizada pelo Comitê de Relações Internacionais da Câmara de Deputados dos Estados Unidos, para introduzir modificação na regulamentação vigente no país para dar preferência à importação de café de melhor qualidade no mercado norte-americano. A reunião foi motivada pela preocupação com os baixos preços do produto nos últimos anos e as implicações negativas para alguns produtores tradicionais (Colômbia e países Centros-Americanos). Vale ressaltar que o Brasil, maior produtor da região e do mundo, não foi convidado a participar, o que reflete a percepção de alguns de que a situação atual se deve a um aumento de produção de café nos últimos anos no Vietnã e no Brasil. Nesse contexto, a idéia de estabelecer padrões de qualidade para a importação pode ser um artifício para dificultar exportações brasileiras do produto.

O café solúvel brasileiro sofre barreiras tarifárias na União Européia. As indústrias dos países concorrentes ou são isentas das taxas de importação, sob alegação de uma política de cooperação ao combate do narcotráfico, ou são taxadas com uma menor alíquota, como no caso do México e Índia. Em 1991, a UE determinou alíquota zero para a Colômbia, Bolívia, Peru e América Central e 9,5\% para o Brasil sobre as exportações de solúvel (SAES; NAKAZONE, 2002).

A indústria de torrefação e moagem está praticamente voltada para o mercado interno. Com relação ao mercado internacional, a inserção desta indústria é bastante restrita, mesmo sendo equacionada a questão da perecibilidade do produto com a embalagem a vácuo. O que explica este fato é a lógica de funcionamento e estratégias das empresas sediadas nos países desenvolvidos: a indústria de torrefação passou de desconcentrada nos anos 70 para moderadamente concentrada no final dos anos 90; e as razões foram às aquisições e fusões ocorridas no período. Segundo Lago (2002 apud SAES; NAKAZONE, 2002), o movimento de consolidação da indústria torrefadora internacional representa uma barreira à inserção das torrefadoras brasileiras nos mercados consumidores, mas as altas margens de lucros recebidas por elas podem viabilizar a exportação de café torrado moído brasileiro diretamente para o varejo internacional, mesmo considerando as tarifas cobradas sobre o produto na UE.

\section{Análise da evolução das exportações}

A cadeia agroindustrial do café constitui um dos setores importantes da economia brasileira pela sua expressiva participação na pauta de exportação e na geração de emprego e de renda e representa, no médio e no longo prazo, um dos principais produtos estratégicos para o país. Além disso, a importância da cafeiculturabrasileirapodeservisualizadapelovolume de produção e pelo consumo interno (TEIXEIRA, 2000). O Brasil é o maior produtor mundial de café arábica, seguido da Colômbia, Guatemala, México e Indonésia. O Vietnã se encontra na posição de maior produtor mundial de café robusta. Os Estados Unidos são os maiores consumidores, seguidos pelo Brasil, Alemanha, e Japão.

A trajetória do café no país é reflexo da dinâmica de sua inserção no cenário mundial. Essa dinâmica, por um lado, é marcada pelas características da cultura, que contrasta períodos de restrição de oferta com épocas de abundância. Por outro lado, há uma clara delimitação entre produtores e consumidores, e apenas o Brasil se encontra nos dois lados do fluxo - é produtor e consumidor significativo (ORMOND; PAULA; FAVERET FILHO, 1999).

A história do mercado mundial de café sempre foi marcada pela sucessão de períodos de escassez de oferta, motivada, em geral, por problemas 
climáticos como seca e geadas, o que faz com que os preços se elevem, e também por períodos de "super oferta", em resposta ao aumento dos preços, seguidos de longos períodos de preços baixos (RESENDE, 2001).

O mercado internacional do café tem uma característica que o difere da maioria das outras mercadorias transacionadas entre os países: enquanto na maioria dos produtos as importações são feitas para suprir a escassez da produção local, no café a maior parte do mercado é composta por países nãoprodutores. A Alemanha assume, nos negócios com o café, a posição de entreposto comercial exercida pela Holanda em outros produtos; as estratégias de reexportação são basicamente de ocupação dos mercados intrablocos econômicos, facilitados pelas zonas de livre comércio e proximidades geográficas. Os compradores colocados também na ponta de venda são em número menor que os produtores, têm tradição de exigir qualidade da matéria-prima importada e podem deslocar as vendas, dificultando a conquista de novos mercados pelos países produtores como a reconquista dos mercados perdidos (ORMOND; PAULA; FAVERET FILHO, 1999).

Para melhor visualização da dinâmica das exportações mundiais do complexo cafeeiro foram feitos cálculos das participações dos principais blocos e regiões exportadores considerando o período de 1999 a 2003, e em seguida, o destino e a participação das exportações brasileiras e paranaenses para o mesmo período. A Tabela 1 mostra que a América do Sul exporta predominantemente café verde $(39,9 \%)$ e dessas exportações, $22,3 \%$ se originam dos países do Mercosul. Na seqüência destacam-se as participações da América Central, Ásia e África com $18,2 \%, 14,1 \%$ e $11,6 \%$, respectivamente. Os países da União Européia são os maiores exportadores mundiais de café torrado $(65,5 \%)$, café solúvel $(42,5 \%)$ e bebidas com café $(17,3 \%)$, também repassam café verde e cascas e peles de café para os mercados regionais. O Nafta tem um mercado diversificado, tanto para importações, como para exportações dos produtos do complexo cafeeiro. No que se refere ao café solúvel, a União Européia também apresenta maior participação das exportações (42,5\%), e em seguida a América do Sul e os Tigres Asiáticos participam do mercado com $18,2 \%$ e $11,4 \%$, respectivamente. Para as exportações mundiais de bebidas com café, a África se destaca com uma participação de 24,9\%, a Ásia com 21,3\%, a União Européia com 17,3\% e o Nafta com $14,3 \%$. As principais regiões/blocos exportadores de café com casca e pele são: África (31,6\%), Oriente Médio (19,2\%), América do Sul (17,3\%), União Européia (16,2\%) e Nafta (11,3\%).

Tabela 1. Participação das exportações mundiais do complexo agroindustrial do café no período de 1999 a 2003.

\begin{tabular}{lccccc}
\hline \multirow{2}{*}{ Regiões/Blocos } & \multicolumn{5}{c}{ Participação (\%) } \\
\cline { 2 - 6 } & Verde & Torrado & Solúvel & Bebidas & Casca e Pele \\
\hline União Européia & 7,1 & 65,5 & 42,5 & 17,3 & 16,2 \\
Nafta & 7,3 & 19,4 & 9,5 & 14,3 & 11,3 \\
Leste Europeu & - & 5,4 & 6,3 & 6,8 & - \\
Efta & - & 2,8 & 3,2 & - & - \\
Oriente Médio & - & 2,8 & - & 9,7 & 19,2 \\
Tigres Asiáticos & 5,0 & 1,2 & 11,4 & 3,8 & 4,3 \\
Mercosul & 22,3 & - & 11,2 & - & - \\
A. do Sul s/ Mercosul & 17,6 & - & 7,0 & & 17,3 \\
África & 11,6 & - & 3,7 & 24,9 & 31,6 \\
Ásia & 14,1 & - & - & 21,3 & - \\
Oceania & 1,5 & - & - & 14,3 & - \\
América Central & 18,2 & - & - & - & - \\
\hline
\end{tabular}

Fonte: Elaborada pelos autores com dados da FAO, 2004. 
As exportações brasileiras concentram-se em café verde e solúvel - o verde representa mais de $90 \%$ do total exportado. A produção de café torrado e moído é voltada para o mercado interno, segmento que detém valor acima de $95 \%$ do consumo total. A grande vantagem do Brasil em relação a seus concorrentes reside no fato de o país produzir todas as qualidades de café, que são suficientes para atender a qualquer demanda. Os principais importadores do café brasileiro são os Estados Unidos, a Alemanha, a Itália e o Japão (RESENDE, 2001).

O destino das exportações brasileiras apresentado na tabela 2 destaca a concentração em café verde, tendo como principal mercado a União
Européia e o Nafta, responsáveis pela compra de aproximadamente $76 \%$ das exportações do tipo café verde, enquanto outros $15 \%$ são comercializados no Leste Europeu e aos Tigres Asiáticos. Os maiores compradores do café torrado estão nas Américas (73,6\%), sendo o principal comprador o Nafta, seguido pelos Tigres Asiáticos e os parceiros comerciais brasileiros da América do Sul e Mercosul. No tipo solúvel, o mercado é bem diversificado com altas participações de toda a Europa Ocidental e o Leste Europeu, assim como os Tigres Asiáticos e o Nafta. As bebidas com café são direcionadas preponderantemente para os Tigres Asiático, sendo os japoneses nossos principais compradores.

Tabela 2. Destino e participação das exportações brasileiras do complexo agroindustrial do café no período de 1999 a 2003 .

\begin{tabular}{lccccc}
\hline \multirow{2}{*}{ Regiões/Blocos } & \multicolumn{5}{c}{ Participação (\%) } \\
\cline { 2 - 6 } & Verde & Torrado & Solúvel & Bebidas & Casca e Pele \\
\hline União Européia & 56,4 & 8,1 & 17,3 & 0,7 & - \\
Nafta & 19,7 & 45,5 & 18,6 & 0,8 & - \\
Tigres Asiáticos & 9,5 & 13,4 & 13,7 & 92,3 & - \\
Leste Europeu & 5,2 & 2,1 & 39,7 & 0,3 & - \\
Oriente Médio & 2,9 & 0,5 & 0,4 & - & - \\
Mercosul & 2,4 & 9,5 & 4,9 & 3,6 & - \\
Efta & 1,9 & - & - & - & - \\
África & 0,9 & 1,5 & 0,6 & & - \\
Oceania & 0,4 & 0,8 & 1,8 & - & - \\
\hline A. do Sul s/ Mercosul & 0,5 & 18,1 & 1,1 & 2,1 & - \\
\hline
\end{tabular}

Fonte: Elaborada pelos autores com dados do MDIC/SECEX, 2004.

Em se tratando das exportações paranaenses do complexo cafeeiro, verifica-se na Tabela 3, um comportamento semelhante ao das exportações brasileiras, onde as exportações paranaenses destinam-se para os principais blocos econômicos que se mostram com especializações distintas por tipo de produto. O café verde é preferido pela União Européia (40,7\%), o café torrado pelo Nafta (51,1\%), o café solúvel pelo Leste Europeu $(41,6 \%)$ e as bebidas com café são destinadas para os Tigres Asiáticos (98,1\%). Quanto às exportações paranaenses de café com casca e pele não são significativas.

As exportações do complexo agroindustrial cafeeiro paranaense estão concentradas em mercados tradicionais, que mantém grande concentração industrial na transformação do produto commodity em produtos de maior valor agregado. Há mercados que preferem o produto industrializado como os Estados Unidos, que se apresenta como o maior mercado para todos os produtos (café verde, torrado, solúvel e bebidas com café) do complexo cafeeiro paranaense. A União Européia tem preferência pelo café verde, visando à industrialização para a exportação de café torrado, solúvel e bebidas com café. Apenas a Alemanha importa café solúvel e a Suíça café torrado do Paraná. 
Tabela 3. Destino e participação das exportações paranaenses do complexo agroindustrial do café no período de 1999 a 2003.

\begin{tabular}{lccccc}
\hline \multirow{2}{*}{ Regiões/Blocos } & \multicolumn{5}{c}{ Participação (\%) } \\
\cline { 2 - 6 } & Verde & Torrado & Solúvel & Bebidas & Casca e Pele \\
\hline União Européia & 40,7 & 1,2 & 13,6 & - & - \\
Nafta & 36,3 & 51,1 & 23,8 & 1,1 & - \\
Mercosul & 12,2 & 33,0 & - & - & - \\
Tigres Asiáticos & 2,3 & 12,7 & 14,4 & 98,1 & - \\
Leste Europeu & 2,3 & 1,6 & 41,6 & - & - \\
África & 2,1 & - & 1,1 & - & - \\
Efta & 1,7 & - & - & - & - \\
A. do Sul s/ Mercosul & 1,6 & - & - & - & - \\
Oceania & - & - & 3,1 & - & - \\
\hline
\end{tabular}

Fonte: Elaborada pelos autores com dados do MDIC/SECEX, 2004.

Para os mercados do Leste Europeu e Ásia o Paraná exporta os produtos café torrado e solúvel. Enquanto as exportações paranaenses de bebidas com café $(92,1 \%)$ são destinadas ao mercado japonês. A análise e os determinantes da dinâmica do mercado internacional do café e das exportações do Brasil e do Paraná serão detalhados em seguida os tipos de café: verde, solúvel, torrado, bebidas com café e café com casca e pele. A seguir discutese a metodologia

\section{Metodologia}

O método para avaliar a competitividade é o modelo Constant-Market-Share (CMS), segundo Leamer e Stern (1970), permite identificar as causas do crescimento das exportações de café. Esta análise enfatiza o desempenho do mercado exportador em relação ao mercado importador. $\mathrm{O}$ modelo CMS atribui o crescimento das exportações, favorável ou desfavorável ao setor exportador, tanto na estrutura das exportações do país quanto em sua competitividade, o suposto é que mantida a parcela de exportação do país, a variação constitui a competitividade.Para a análise de market-share, a década de 90 será subdividida em três, trabalhandose com valores médios, quais sejam: o primeiro subperíodo vai de 1990 a 1993, o segundo de 1994 a 1998 e o terceiro de 1999 a 2003.
Primeiramente identificou-se a evolução da concentração das exportações paranaenses para os mercados de destino e posteriormente utilizouse o modelo Constant Market Share (CMS) para explicar o crescimento das exportações de ambos os complexos. O modelo CMS serviu para decompor as fontes de crescimento das exportações e identificar os elementos responsáveis pelo comportamento, a competitividade e os fatores de influenciam o desempenho das exportações do complexo cafeeiro paranaense.

A hipótese implícita no modelo CMS é que o país aumenta sua participação no comércio mundial e suas exportações crescem acima da média quando: a) estão concentradas em mercadorias cujas demandas crescem mais velozmente; b) são destinadas a mercado/países cuja demanda cresce relativamente mais rápido; c) estão se beneficiando de outros ganhos de competitividade, além dos mencionados.

O método atribui o crescimento favorável/ desfavorável das exportações ao setor exportador, tanto na estrutura de exportações do país quanto em sua competitividade. O modelo supõe que, mantida a parcela de exportação do país, a variação verificada ocorre em função da competitividade, sendo que a decomposição do crescimento das exportações é feita de acordo com os seguintes 
fatores: a) crescimento do comércio internacional; b) composição da pauta de exportações; c) destino das exportações; d) competitividade, determinada pelo resíduo das demais.Atribui-se ao resíduo negativo o fracasso de manter-se no comércio e ao resíduo positivo o sucesso na ampliação da participação do comércio internacional.

O modelo permite a análise por componentes e pelo comportamento do produto no mercado de destino, indicando os mercados onde o país é mais competitivo. Embora se faça uso de séries passadas, o método CMS apresenta a possibilidade de serem feitas estimativas sobre o direcionamento e a concentração do setor exportador em produtos mais dinâmicos

$\mathrm{V}^{*} . .-\mathrm{V} . .=\mathrm{rV} . .+{ }_{\mathrm{i}}(\mathrm{ri}-\mathrm{r}) \mathrm{Vi} .+\sum_{\mathrm{i} j} \Sigma(\mathrm{rij}-\mathrm{ri}) \mathrm{Vij}+\mathrm{ij}_{\mathrm{j}} \Sigma\left(\mathrm{V}^{*} \mathrm{ij}-\mathrm{Vij}-\mathrm{rij} \mathrm{Vij}\right)$ (a)

(b)

(c)

(d)

Em que:

V.. = valor total das exportações do país Z, período 1;

$\mathrm{V}^{*}$.. = valor total das exportações do país $\mathrm{Z}$, período 2;

$\mathrm{r}=$ incremento das exportações mundiais do período 1 para o período 2 .

$\mathrm{V}_{\mathrm{ij}}=$ valor total das exportações do produto i do país $\mathrm{Z}$, para o país j, período 1 ;

$\mathrm{V}^{*}{ }_{\mathrm{ij}}=$ valor total das exportações do produto i do país Z, para o país j, período 2;

$\mathrm{r}_{\mathrm{ij}}=$ incremento das exportações mundiais do produto i para o país j do período 1 para o período 2 .

Os quatro efeitos diferenciados são relacionados a seguir, sendo os de (a) e (b) relacionados a fatores externos, e os efeitos (c)e(d) a fatores internos. Assim sendo: a) Efeito crescimento do comércio mundial - incremento observado se as exportações do país Z tiverem crescido à mesma taxa de crescimento do comércio mundial; b) Efeito composição da pauta de exportação - mudanças na estrutura da pauta com concentração em produto com crescimento de demanda mais ou menos acelerado. Indica que se as exportações mundiais do produto $i$ aumentam mais do que a média mundial para todas as mercadorias exportadas, $(\mathrm{ri}-\mathrm{r})$ é positivo.

O efeito composição da pauta será positivo se as exportações do país $Z$ estiverem concentradas no produto de maior expansão ou quando a taxa de crescimento for superior à média mundial. c) Efeito destino das exportações - mudanças decorrentes de exportações de produtos para mercados de crescimento mais ou menos dinâmicos. Será positivo se o país $Z$ tiver concentrado suas exportações em mercados que experimentaram maior dinamismo no período analisado, e negativo se concentrado em regiões estagnadas. d) Efeito residual, representando a competitividade - que reflete a diferença entre o crescimento atual e o crescimento que teria ocorrido nas exportações do país $\mathrm{Z}$ se tivesse sido mantido a parcela de exportação de cada bem para cada país. Significa que uma economia é competitiva na produção de determinada mercadoria quando consegue pelo menos se igualar aos padrões de eficiência vigentes no resto do mundo quanto à utilização de recursos e à qualidade do bem.

A diferença entre o crescimento das exportações verificadas pelo modelo CMS e o crescimento efetivo é atribuída ao efeito competitividade, e a medida desse efeito relaciona-se a mudanças nos preços relativos. Quando um país deixa de manter sua parcela no mercado mundial, o termo competitividade torna-se negativo e seus preços crescem diante dos preços dos competidores. Os produtos mais representativos do complexo cafeeiro são os seguintes: café verde, café torrado, café solúvel e bebidas com café.

\section{Resultados e discussão}

A aplicação do modelo CMS às exportações brasileiras e paranaenses permitiu analisar a decomposição e a contribuição dos efeitos relacionados ao crescimento do comércio mundial, composição da pauta de exportações, destino das exportações e competitividade no período de 1990 a 2003. 
A Tabela 4 apresenta os resultados do modelo CMS, no período de 1990 a 2003, em que o desempenho das exportações brasileiras do complexo agroindustrial do café foi atribuído aos efeitos do crescimento do comércio mundial e da competitividade brasileira. Observa-se uma variação positiva nas exportações de café, sendo a mais expressiva no período de 1994/98. A participação das exportações brasileiras (Market-Share) no comércio mundial cresceu, passando de 17,1\% no primeiro período e terminando com $18,2 \%$, considerando todo o período.

Tabela 4. Taxas e fontes de crescimento das exportações brasileiras do complexo agroindustrial café, em \%.

\begin{tabular}{lccc}
\hline \multirow{2}{*}{ Indicadores } & \multicolumn{3}{c}{ Períodos } \\
\cline { 2 - 4 } & 1990 a 93 & 1994 a 98 & 1990 a 93 \\
\cline { 2 - 4 } & 1994 a 98 & 1999 a 03 & 1999 a 03 \\
\hline a) Taxas de crescimento & 130,6 & $(48,6)$ & 15,7 \\
Exportações mundiais & 97,8 & $(33,5)$ & 24,0 \\
Exportações brasileiras & 17,1 & 17,9 & 18,2 \\
Market-Share & & & \\
& & & \\
b) Fontes de crescimento & 66,1 & $(73,0)$ & 24,5 \\
Crescimento do comércio mundial & 1,1 & $(1,8)$ & $(10,3)$ \\
Composição da pauta de exportações & $(8,4)$ & 179,3 & $(13,9)$ \\
Destino das exportações & 41,2 & 99,7 \\
Competitividade & &
\end{tabular}

Fonte: Elaborada pelos autores, 2005.

A decomposição das fontes de crescimento das exportações brasileiras do complexo cafeeiro indicou que no primeiro período, $66,1 \%$ das exportações de café foi atribuído ao efeito do crescimento do comércio mundial, $41,2 \%$ ao efeito da competitividade eapenas $1,1 \%$ à composição dapauta de exportações. Quanto ao destino das exportações o efeito foi nulo, indicando necessidade de ampliar mercados. No segundo período indicou que o efeito crescimento do comércio mundial e a composição da pauta inibiram o crescimento das exportações brasileiras. O aumento da competitividade de $41,2 \%$ para $179,3 \%$ e $99,7 \%$ no geral, contribuiu para ampliar a participação brasileira nos mercados existentes e em novos mercados. A competitividade e o crescimento do mercado mundial foram responsáveis pela manutenção do crescimento das exportações brasileiras no mercado mundial.

O crescimento efetivo das exportações brasileiras deve-se ao efeito da competitividade, o que retrata forte associação do desempenho das exportações brasileiras de café com o dinamismo do comércio internacional. O crescimento do comércio mundial e a abertura de novos mercados facilitaram a penetração do complexo agroindustrial brasileiro no mercado exterior. A pauta de exportações mantevese concentrada no café verde e solúvel, indicando que a tendência de diversificação na composição da pauta de exportações ainda é pequena.

ATabela 5 mostra que no primeiro período, $63,5 \%$ do crescimento das exportações paranaenses foram atribuídas ao efeito do crescimento do comércio mundial, $27,1 \%$ ao efeito da competitividade e 3,0\% é atribuído à composição da pauta de exportações. A diversificação de mercados funcionou como mecanismo importante para manter e ampliar a participação das exportações paranaenses. Já no segundo período, a taxa de crescimento do comércio mundial negativa influenciou a redução das exportações paranaenses. Mesmo com o maior dinamismo da pauta de exportações, a participação das exportações paranaenses (Market-Share) do complexo cafeeiro caiu no segundo período para $1,6 \%$, mas no geral permanece com $1,7 \%$. 
Tabela 5. Taxas e fontes de crescimento das exportações paranaenses do complexo agroindustrial café, em \%.

\begin{tabular}{lccc}
\hline & \multicolumn{3}{c}{ Períodos } \\
\cline { 2 - 4 } Indicadores & 1990 a 93 & 1994 a 98 & 1990 a 93 \\
\cline { 2 - 3 } & 1994 a 98 & 1999 a 03 & 1999 a 03 \\
\hline a) Taxas de crescimento & 130,6 & $(48,6)$ & 15,7 \\
Exportações mundiais & 105,7 & $(50,5)$ & 1,9 \\
Exportações paranaenses & 1,7 & 1,6 & 1,7 \\
Market-Share & & & \\
& & & 19,0 \\
b) Fontes de crescimento & 63,5 & 31,4 & 35,3 \\
Crescimento do comércio mundial & 3,0 & 67,1 & 89,6 \\
Composição da pauta de exportações & 6,5 & 99,5 & $(43,9)$ \\
Destino das exportações & 27,1 & & \\
Competitividade & & & \\
\hline
\end{tabular}

Fonte: Elaborada pelos autores, 2005.

De acordo com Sereia e Camara (2002), a análise do modelo CMS ressalta a fragilidade de políticas internas direcionadas à abertura de novos mercados e à divulgação do produto paranaense no exterior. Durante o período em estudo, a diversificação dos mercados, assim como a composição da pauta e o crescimento do mercado internacional foram as principais fontes de crescimento das exportações do complexo agroindustrial paranaense. $\mathrm{O}$ crescimento do comércio e da demanda mundial facilitou a penetração dos produtos do complexo agroindustrial paranaense no mercado exterior.

O desempenho das exportações do complexo agroindustrial cafeeiro paranaense pode ser explicado pelo rompimento do Acordo Internacional do Café, a extinção do Instituto Brasileiro de Café, a abertura econômica, a entrada do Brasil no bloco econômico do Mercosul e a implantação do Plano Real. Tais fatores contribuíram para o declínio da participação do país no mercado internacional de café verde, em volume exportado e em parcela de mercado, nos primeiros anos da década de 90 , que repercutiu no resultado de todo o período, devido à perda de competitividade (RESENDE, 2001).

Conforme os resultados descritos na Tabela 6, o crescimento efetivo das exportações paranaenses de café verde, entre 1990 e 1998, foi atribuído ao crescimento do comércio mundial, já que este apresentou valor positivo (104,7\%). O efeito destino das exportações, por sua vez, apresentou-se negativo $(9,3 \%)$, e indica pequena participação do café verde paranaense no mercado dos países de destino das exportações paranaenses. 
Tabela 6. Taxas e fontes de crescimento das exportações paranaenses de café verde, em \%.

\begin{tabular}{lccc}
\hline & \multicolumn{3}{c}{ Períodos } \\
\cline { 2 - 4 } Indicadores & 1990 a 93 & 1994 a 98 & 1990 a 93 \\
\cline { 2 - 3 } & 1994 a 98 & 1998 a 03 & 1998 a 03 \\
\hline a) Taxas de crescimento & 132,2 & $(56,2)$ & 1,6 \\
Exportações mundiais & 26,3 & $(41,7)$ & $(35,8)$ \\
Exportações paranaenses & 0,6 & 0,6 & 0,6 \\
Market-Share & & & \\
& & & 1,2 \\
b) Fontes de crescimento & 104,7 & 70,2 & 77,3 \\
Crescimento do comércio mundial & 9,3 & 126,2 & 21,5 \\
Destino das exportações & $(14,0)$ & & \\
Competitividade & & & \\
\hline
\end{tabular}

Fonte: Elaborada pelos autores, 2005.

O efeito competitividade foi negativo $(14,0 \%)$, que, segundo Resende (2001), pode estar associada à restrição da oferta, decorrente de geadas; ao endividamento em geral do setor; à baixa capacidade de coordenação de seus agentes, para se adequarem ao novo padrão competitivo do mercado; e essa perda está refletida nas estatísticas que indicam declínio ou estagnação do consumo de café commodity tanto no mercado norte-americano como no europeu, maiores compradores do Brasil. Ao mesmo tempo, verificase o crescimento da demanda de cafés especiais, à qual o Brasil apresenta dificuldades em atender, mesmo dispondo de um parque cafeeiro complexo e diversificado, dificuldade que pode estar associada a conflitos que permeiam as transações do sistema agroindustrial do café.

Apesar da drástica redução das exportações mundiais no segundo período terem influenciado negativamente a taxa de crescimento das exportações mundiais de café, o Paraná conseguiu manter o mesmo nível de participação das exportações (Market-Share) de café verde no mercado mundial, ainda que baixo $(0,6 \%)$. Isso é resultado tanto do efeito competitividade significativo (126,2\%), quanto do efeito destino das exportações $(70,2 \%)$.

De acordo com Resende (2001), a perda de participação pode estar relacionada com a perda de imagem do café brasileiro, que, apesar de o país possuir a vantagem de ter uma rede comercial montada que lida com grandes quantidades, ainda atua com o rótulo de vender defeitos no café. Compete ao segmento exportador resgatar a imagem do produto no mercado externo, de forma a conquistar as parcelas perdidas nos tradicionais mercados importadores e conquistar novas fatias de mercado, com vistas em oferecer cafés com qualidade.

O mercado internacional de café processado, torrado e solúvel, é fortemente influenciado por políticas protecionistas dos países importadores, que resulta em competitividade desigual entre as empresas processadoras italianas, alemãs e americanas (AMARAL, 2001). A indústria brasileira por mais que se esforce não consegue se estabilizar no patamar competitivo exigido pelo mercado, mesmo tendo seu parque industrial compatível ao concorrente internacional, tal deformação aparece no resultado negativo de competitividade dos cafés processados quando se considera o período em estudo deste trabalho. A prática do Draw Back (reexportação), principalmente pelos europeus, requer políticas de incentivos e facilidades a entrada de café verdes para alimentar as indústrias processadoras, contrário ao que se observa para o produto processado oriundo do exterior.

A Tabela 7 apresenta os resultados da decomposição das exportações paranaenses de café solúvel. 
Tabela 7. Taxas e fontes de crescimento das exportações paranaenses de café solúvel, em \%.

\begin{tabular}{lccc}
\hline & \multicolumn{3}{c}{ Períodos } \\
\cline { 2 - 4 } Indicadores & 1990 a 93 & 1994 a 98 & 1990 a 93 \\
\cline { 2 - 4 } & 1994 a 98 & 1998 a 03 & 1998 a 03 \\
\hline a) Taxas de crescimento & 127,4 & $(28,0)$ & 38,9 \\
Exportações mundiais & 179,0 & $(52,1)$ & 25,2 \\
Exportações paranaenses & 7,7 & 7,0 & 6,9 \\
Market-Share & & & \\
& & & \\
b) Fontes de crescimento & 45,7 & 26,6 & 57,1 \\
Crescimento do comércio mundial & 5,9 & 131,9 & $(42,5)$ \\
Destino das exportações & 48,4 & & \\
Competitividade & & & \\
\hline
\end{tabular}

Fonte: Elaborada pelos autores, 2005.

No primeiro período $48,4 \%$ do seu crescimento foi atribuído ao efeito da competitividade e $45,7 \%$ ao efeito do crescimento do comércio mundial. Nota-se que a participação das exportações paranaenses (MarketShare) de café solúvel diminuiu no período estudado, de $7,7 \%$ para $7,0 \%$. Esse fato pode ser explicado pela redução das exportações paranaenses ocasionada pelo crescimento negativo do comércio mundial, mesmo com o aumento da competitividade das exportações de $48,4 \%$ para $131,9 \%$ no período seguinte.

A análise do modelo CMS permitiu verificar que há falhas nas políticas e estratégias internas para abertura de novos mercados no exterior. Além disso, a competitividade e o crescimento do comércio mundial foram as principais fontes de crescimento das exportações paranaenses de café solúvel.
$\mathrm{Na}$ Tabela 8 aparecem os resultados da decomposição das exportações paranaenses de café torrado, mostrando seu crescimento diferenciado ao longo do período estudado.

O desempenho indica que as exportações paranaenses foram influenciadas pelas crises da economia mundial no final da década de 90 . A participação das exportações paranaenses de café torrado no comércio mundial, embora tenha crescido no segundo período, ainda é muito baixa, não conseguindo ultrapassar $1,0 \%$ das exportações mundiais. No primeiro período, praticamente todo o crescimento das exportações paranaenses foi atribuído ao efeito da competitividade $(98,6 \%)$ e $1,2 \%$ ao efeito do crescimento do comércio mundial.

Tabela 8. Taxas e fontes de crescimento das exportações paranaenses de café torrado, em \%.

\begin{tabular}{lccc}
\hline & \multicolumn{3}{c}{ Períodos } \\
\cline { 2 - 4 } Indicadores & 1990 a 93 & 1994 a 98 & 1990 a 93 \\
\cline { 2 - 4 } & 1994 a 98 & 1998 a 03 & 1998 a 03 \\
\hline a) Taxas de crescimento & 119,8 & $(9,4)$ & 49,8 \\
Exportações mundiais & 10159,0 & $(33,9)$ & 98,5 \\
Exportações paranaenses & 0,0 & 0,1 & 0,0 \\
Market-Share & & & \\
& & $(14,2)$ & 6719,7 \\
b) Fontes de crescimento & 1,2 & $(8,9)$ & 505,7 \\
Crescimento do comércio mundial & $(0,2)$ & 123,2 & $(7125,4)$ \\
Destino das exportações & 98,6 & & \\
Competitividade & & & \\
\hline
\end{tabular}

Fonte: Elaborada pelos autores, 2005. 
Em contrapartida, no segundo período, os efeitos crescimento do comércio mundial e destino das exportações inibiram o crescimento das exportações paranaenses, enquanto o aumento da competitividade agiu de forma a compensar e a elevar a participação das exportações paranaenses no mercado mundial. A baixa participação paranaense na exportação de café torrado no início dos anos 90 e a forte proteção internacional para os cafés processados, inibiram o esforço competitivo da indústria paranaense e crescimento do comércio mundial apresenta-se como maior fonte de explicação do crescimento das exportações desse produto.

\section{Conclusão}

O café, desde o início do século XIX, desempenha um importante papel na economia mundial e o Brasil tem ocupado, historicamente, posição de maior produtor e exportador mundial de café. Pelo fato de ser uma cultura que utiliza tecnologia intensiva em trabalho, o café constitui-se em uma atividade geradora de emprego e de renda, sobretudo quando se consideram as demais atividades ao longo de toda a cadeia do produto. Além disso, o café é uma importante fonte de geração de divisas para geração de receitas necessárias à importação de outros bens essenciais e o superávit da balança comercial favorável ao desenvolvimento econômico.

O setor exportador é afetado pelas mudanças das regras no mercado internacional do café e, também pelas práticas protecionistas de alguns países consumidores. Está, exposto aos padrões de consumo externo e à prática competitiva de grandes corporações internacionais. A falta de coordenação entre os segmentos do agronegócio, as oscilações dos preços internacionais e as distorções tributárias são fatores determinantes da participação das exportações brasileiras de café no comércio internacional.

O Brasil é maior produtor e ofertante mundial de café arábica, tem garantido a manutenção e o crescimento da participação no mercado internacional devido ao custo de produção mais baixo em seus estados produtores. Assim, o crescimento efetivo das exportações paranaenses deve-se ao efeito da competitividade, o que retrata forte associação do desempenho das exportações paranaenses de café com o dinamismo do comércio internacional. $\mathrm{O}$ crescimento do comércio mundial e a abertura de novos mercados facilitaram a penetração do complexo agroindustrial cafeeiro no mercado internacional.

Apesar das exportações brasileiras do complexo cafeeiro terem aumentado em apenas 2,5\% entre 1999 a 2003, o Brasil ainda detém a hegemonia na oferta mundial de café $(17,9 \%)$. Os principais países exportações de café solúvel são: Alemanha (18,4\%), Brasil(11,1\%), França (5,8\%) e Reino Unido (5,2\%). Quanto ao café torrado, os principais exportadores são: Itália, Alemanha, Estados Unidos e Bélgica. Enquanto, os maiores exportadores de bebidas com café são: Costa do Marfim , Austrália, Líbano, Índia e Estados Unidos. Para o café mais simples, com casca e pele os maiores exportadores são: Iemen (19,0\%), Peru (17,3\%), Zimbabwe (12,5\%) e Estados Unidos (11,3\%); mas vale destacar que as exportações brasileiras desse produto se destinam para os Estados Unidos, Japão e Uruguai.

Dos tipos de café exportados pelo complexo agroindustrial paranaense, o café verde é o produto preferido pelos mercados da União Européia e Estado Unidos, que passam a ser grandes exportadores de café torrado, solúvel e de bebidas com café. Os grandes compradores do café solúvel paranaense foram os Estados Unidos (22,5\%), Leste Europeu (32,5\%) e Japão (10,3\%). Enquanto para o café torrado paranaense, os principais mercados foram as Estados Unidos (51\%) e o restante é muito pulverizado entre os países do Mercosul (33,1\%) e Ásia (12,2\%). Quanto, às exportações de bebidas com café paranaenses, ainda é de pouca expressão, atende exclusivamente aos mercados japonês $(92,1 \%)$ e norte americano $(1,1 \%)$.

A participação das exportações paranaenses (Market-Share) foi influenciada pelas políticas 
protecionistas e práticas adversas ao comércio internacional. Com a retomada do crescimento mundial a partir de 1995, seguida de sucessivas crises financeiras de significativas proporções, que abalaram a credibilidade internacional, têm-se uma redução no ritmo do processo de crescimento, o que acabou por direcionar os fluxos de capitais mundiais. Com isso, o comércio mundial se retraiu e o processo evolutivo das exportações paranaenses do setor cafeeiro passou a ser sustentado por estratégias interna de diversificação da pauta de exportação e pelo pequeno crescimento da competitividade comercial.

Embora tenha aumentado à competitividade das exportações de café verde paranaense, houve redução desuaparticipaçãono comérciomundialemfunção da crescente oferta da commodity principalmente, pelos países asiáticos e africanos. Quanto às exportações de café solúvel paranaenses perderam participação no mercado internacional e simultaneamente houve uma tendência à desconcentração dos países de destino. As exportações paranaenses de café torrado ganhou participação no comércio mundial sustentada pelo ganho de competitividade, mas ainda são muito baixas e inexpressivas diante da demanda mundial. As exportações paranaenses de bebidas com café se mantiveram estáveis para o reduzido número de países de destino Japão, Estados Unidos, e Argentina.

A participação brasileira, assim como a paranaense foram afetadas no mercado mundial de café, em parte, pela política de valorização de preços praticada pelo país; pela regulação do mercado, que ocorreu no período dos Acordos Internacionais; pelos momentos de valorização da moeda nacional, fazendo com que o Brasil reduzisse sua cota de exportação e estimulando a produção dos países concorrentes; e pela falta de políticas de coordenação e incentivos ao setor. $\mathrm{O}$ endividamento do setor, perda de qualidade do café paranaense (brasileiro), ausência de marketing externo, melhor divulgação do produto e aumento do consumo interno também justificam a perda de dinamismo do produto no mercado internacional.
Dadas as alterações ocorridas no comércio mundial de café nos anos 90, a principal variável de competição externa disponível é investir na qualidade dos grãos e em processos de produção para que o café brasileiro ganhe status de produto diferenciado. Os tipos de cultivos devem se adequar aos padrões e exigência do consumidor estrangeiro que vem aumentando sua preferência por produtos de origem natural ou orgânico, considerados sabores finos e diferenciados do produto tradicional em qualidade e preço. Além disso, faz-se necessária a formulação de políticas mais apropriadas ao país, para que não fique subordinado às políticas conjuntas implementadas pelos Acordos Internacionais.

\section{Referências}

AMARAL, S. Café requentado. Folha de São Paulo, São Paulo, 30 abr. 2001. Jel: F. Disponível em: <www. race.nuca.ie.ufrj.br/journal/a/a.htm>. Acessado em: 07/09/2005.

BARREIRAS aos produtos e serviços brasileiros. Washington: Embaixada do Brasil em Washington, 2002.

BAUMANN, R. Uma visão econômica da globalização. In: BAUMANN, R. (Org.). O Brasil e a economia global. Rio de Janeiro: Campus, 1996. p.33-54.

BIELSCHOWSKY, R.; STUMPO, G. A internacionalização da indústria brasileira: números e reflexões depois de alguns anos de abertura. In: BAUMANN, R. (Org.). O Brasil e a economia global. Rio de Janeiro: Campus, 1996.

BRAGANÇA, G. G. F. Poder de mercado do café brasileiro nos EUA: abordagem via demanda residual. 2000. Dissertação (Mestrado em Economia) - Fundação Getúlio Vargas, Rio de Janeiro.

CARVALHO, M. A.; SILVA, C. R. L. Economia internacional. São Paulo: Saraiva, 2000.

CASTRO, A. M. G.; LIMA, S. M. V.; HOEFLICH, V. A. Cadeias produtivas. Curitiba: TECPAR, 2002.

COUTINHO, L.; FERRAZ, J. C. Estudo da competitividade da indústria brasileira. Campinas: Papirus, 1994.

DUNNING, john. the ecletic paradigm of international production: a reestatment and some possible extensions. Journal of International Marketing Business Studies, Londres, v. 19, n. 1, p. 1-31, 1988. 
FERRARO, F.; SEREIA, V. J.; CAMARA, M. R. G. O comportamento e a competitividade do complexo soja nas exportações paranaenses. In: CONGRESSO DE ECONOMIA E SOCIOLOGIA RURAL, XLI, 2003. Juiz de Fora. Anais eletrônico... Juiz de Fora: SOBER, 2003. CD-ROM.

FERRAZ, J. C.; KUPFER, D.; HAGUENAUER, L. Made in Brazil: desafios competitivos para a indústria. Rio de janeiro: Campus, 1995.

GONÇALVES, R.; BAUMANN, R.; PRADO, L. C. D.; CANUTO, O. A nova economia internacional: uma perspectiva brasileira. Rio de Janeiro: Campus, 1998.

GONÇALVES, R. Globalização financeira, liberalização cambial e vulnerabilidade externa da economia brasileira. In: BAUMANN, R. (Org.). O Brasil e a economia global. Rio de Janeiro: Campus, 1996. p.133-165.

GRASSI, R. A. Comentários sobre a aplicação empírica do conceito estrutural de competitividade. Leituras de Economia Política, Campinas, n. 4, p. 3-22, jun. 1997.

GUIMARÃES, E. P. Evolução das teorias de comércio internacional. Estudos em Comércio Exterior ECEX/ IE/UFRJ, v.1, n.2, p.01-19, jan/jun, 1997. (ISSN 14137976). Disponível em: <http://www.ie.ufrj.br/ecex/pdfs/ evolucao_das_teorias_de_comercio_internacional.pdf $>$. Acessado em: 12/09/2005.

KENEN, P. B. Economia internacional: teoria e política. Rio de Janeiro: Campus, 1998.

KRUGMAN, P. R.; OBSTFELD, M. Economia internacional: teoria e política. São Paulo: Makron Books, 1999.

KUPFER, D. Padrões de concorrência e competitividade. In: ENCONTRO NACIONAL DE ECONOMIA, 20, 1992, Campos do Jordão. Anais... Brasília ANPEC, 1992. p. 261-281.

LEAMER, E. E.; STERN, R. M. Constant-market-share analysis of export growth. In: Quantitative international economics. Boston: Allyn and Bacon, 1970. p. 171-183.
MAIA, J. M. Economia internacional e comércio exterior. São Paulo: Atlas, 1998.

ORMOND, J. G. P.; PAULA, S. R. L.; FAVERET FILHO, P. Café: (Re) conquista dos mercados. BNDES Setorial, Rio de Janeiro, n. 10, p. 3-56, set. 1999.

PORTER, M. E. Estratégia competitiva: técnicas para análise de indústrias e da concorrência. Rio de Janeiro: Campus, 1986.

RESENDE, R. M. Relações entre o Mercosul e as exportações brasileiras de café. 2001. Dissertação (Mestrado em Economia Aplicada) - Universidade Federal de Viçosa, Viçosa.

RICARDO, D. Princípios de economia política e tributação. São Paulo: Abril Cultural, 1982. (Os Economistas).

SAES, M. S. M.; NAKAZONE, D. Cadeia: café. In: Estudo da Competitividade das Cadeias Produtivas Integradas no Brasil: Impacto do Livre Comércio. Campinas: UNICAMP-IE-NEIT/MCT/FINEP, 2002.

SALVATORE, D. Economia internacional. Rio de Janeiro: LTC, 2000.

SEREIA, V. J.; CAMARA, M. R. G. O comportamento das exportações do complexo agroindustrial paranaense. In: ENCONTRO DE ECONOMIA PARANAENSE. 1., 2002, Maringá. Anais... Maringá: UEM, 2002.

SCHUMPETER, J. A. Teoria do desenvolvimento econômico. São Paulo: Nova Cultural, 1988. (Os Economistas).

TEIXEIRA, T. D. Política estratégica para a cafeicultura brasileira. In: SIMPÓSIO DE PESQUISA DOS CAFÉS DO BRASIL, 1., 2000, Poços de Caldas. Anais... Brasília: Embrapa Café - MINASPLAN, 2000. p. 169-193.

WEDECKIN, I. Os agriclusters e a construção da competitividade local. In: CONGRESSO BRASILEIRO DE AGRIBUSINESS, 1., 2002, São Paulo. Anais... São Paulo: ABAG, 2002. p. 43-55.

WILLIAMSON, J. A economia aberta e a economia mundial: um texto de economia internacional. Rio de Janeiro: Campus, 1989. 